\title{
Presencias y referencias del cancionero infantil en el teatro de García Lorca
}

\section{Appearances and References in Children's Song Book in García Lorca's Theater}

\author{
Pedro Cerrillo Torremocha y César SÁnChez OrTIZ \\ Universidad de Castilla-La Mancha \\ $\dagger /$ cesar.sortiz@uclm.es
}

ORCID ID: 0000-0001-6373-7016 / 0000-0002-1534-8822

\begin{abstract}
Federico Garcia Lorca introduces nursery RESUMEN: Federico García Lorca retoma canciones rhymes in his plays, and he refers to these songs in infantiles en sus obras teatrales, incluso él mismo other plays. His interest in retaking these songs was hace referencia en otras obras de su interés por esas evident from his childhood and, indeed, already in canciones. El deseo por retomar las canciones during his adolescence he recorded and rewrote infantiles se manifestó desde su infancia e, incluso, en popular poetry. Much of the inspiration for his poetry su adolescencia recogió y reescribió poesía popular. comes from the popular tradition.

Mucha de la inspiración para su poesía viene de la tradición popular.
\end{abstract}

KEYwORDS: Children's song books, popular, Garcia PALABRAS-ClAVE: cancionero infantil, popular, Lorca, theater, poetry

García Lorca, teatro, poesía

En la formación literaria de García Lorca, como en la de los demás compañeros del Grupo del 27, tuvieron mucha importancia sus lecturas (las de los clásicos de la Edad de Oro y las de los maestros más cercanos a su tiempo: Bécquer, Rubén Darío, Antonio Machado y Juan Ramón Jiménez), pero - a diferencia de los demás poetas del 27- su poesía empezó a cobrar cuerpo y forma desde la infancia, en la que sintió, vivió, escuchó y entonó canciones infantiles de diverso tipo.

\section{INFANCIA Y CANCIONES EN LA VIDA DEL POETA}

Desde muy pequeño, Federico se sintió muy atraído por la música ${ }^{1}$ y las canciones populares, demostrando gran facilidad para aprender y memorizar textos y melodías, que oía cantar a las mujeres de su familia o de su pueblo. Su hermano Francisco (Vid. 1980: 13 y ss.) ha hablado, en más de una ocasión, de «nuestro folclore infantil», refiriéndose al de los cuatro hermanos García Lorca (Federico era el mayor), quienes, junto a primos y niños del pueblo, jugaban a corros y filas, cantaban romances y entonaban canciones populares, que solían aprender de boca de su madre o de otras mujeres de su entorno más cercano, en la infancia que pasaron en Fuentevaqueros. El propio Federico se refirió a ello unos meses antes de su muerte, el 23 de diciembre de 1935, en el homenaje que poetas y críticos catalanes le tributaron en el hotel Majestic de Barcelona con motivo del éxito que tuvo el

\footnotetext{
${ }^{1}$ El niño Federico, dice su hermano Francisco, tenía una especial facilidad para la música: «Entonaba canciones con singular afinación antes de poder articular sonido» (1980: 61).
} 
estreno de Doña Rosita la soltera o el lenguaje de las flores; allí, Federico, agradecido, se refirió a las criadas de su infancia como las grandes protagonistas de esas vivencias folclóricas infantiles: «"La Colorina", Anilla "La Juanera", que me enseñaron oralmente los romances, leyendas y canciones que despertaron mi alma de poeta» (Cano, 1988: 151). Criadas, nodrizas y «otras sirvientas más humildes — dijo en otra ocasión- que están realizando hace mucho tiempo la importantísima labor de llevar el romance, la canción y el cuento a las casas de los aristócratas y burgueses». (García Lorca, 1996, III: 117)

Su amigo y compañero de generación, Jorge Guillén, dijo que la infancia vivida por Federico siempre estuvo en la raíz misma de su poesía:

La infancia, libre, sin vínculos útiles, sin metas interesadas, retozando, triscando, derrocha espíritu: juega. Federico guardaba una agilísima facultad de juego, procedente de aquel abril propicio al canto: «En abril de mi infancia yo cantaba» (Libro de poemas: «Balada triste»). Esta conciencia de tesorero — porque esa mina del ayer infantil es un tesoro- no quitaba espontaneidad; más bien fortalecía su ímpetu. Y jugaba, jugaba a sus juegos de muchacho y de poeta con las cosas y con las frases (...) Federico mostraba, sin lugar a dudas, cómo la libertad, el desinterés, la pureza, la alegría de sus juegos, allá en su Edad de Oro, favorecía la virtud creadora de su edad sin oro. (Guillén, 1974: XIX)

La facilidad y la espontaneidad del niño Federico para jugar y para ejercer libremente la creatividad, y para despertar la risa o el llanto, son perceptibles también en el adulto Federico, en el García Lorca escritor: buenos ejemplos de ello serían las diversas nanas que compuso, o las «Canciones infantiles» (incluidas en su libro Canciones), algunas de ellas muy conocidas, como «Canción china en Europa», «El lagarto está llorando» 0 «Caracola», o los versos que aparecen en las magníficas farsas «para guiñol» (de las que El retablillo de don Cristóbal es, quizá, el ejemplo más representativo). No obstante, precisa Guillén (1974: $\mathrm{XXI}$ ), en Federico «lo primordial no es la niñez como tema, sino como actitud».

Desde niño, Federico García Lorca hizo gala de su capacidad para el entusiasmo y la pasión, así como de una memoria excepcional y un gran poder de comunicación, rasgo que pudiera haber heredado de su abuela paterna, Isabel Rodríguez, quien, según testimonio de Francisco García Lorca (1980: 51) tenía esa chispa que se encendía casi con su mera presencia; una chispa similar a la de Federico, reconocible en su capacidad para ser el centro de atención de cualquier reunión, con su simpatía, su teatralidad desbordante y su magnetismo.

Quizá como consecuencia inevitable de esa infancia vivida tan intensamente, el interés de Lorca por la poesía popular se extendió a la de particular tradición infantil. Él mismo (1996, I: 59), en las «Palabras de justificación» a su Libro de poemas dice:

Ofrezco en este libro... la imagen exacta de mis días de adolescencia y juventud, esos días que enlazan el instante de hoy con mi misma infancia reciente (...) Sobre su incorrección, sobre su limitación segura, tendrá este libro la virtud... de recordarme en todo instante mi infancia apasionada correteando desnuda por las praderas de una vega sobre un fondo de serranía.

Palabras que también pueden entenderse en los cuatro primeros versos de la «Canción primaveral», contenida en el citado libro:

Salen los niños alegres

de la escuela,

poniendo en el aire tibio 
del abril canciones tiernas (...)

(García Lorca, 1996, I: 70)

Pasada la infancia y la adolescencia, el interés de Federico por la poesía de tradición popular se intensificó, corroborando esos antecedentes infantiles, pues recogió de la tradición oral, recuperando, reescribiendo y fijando por escrito, composiciones que estaban vivas en el pueblo por las que él sentía una especial fascinación: «A la víbora del amor», «Los pelegrinitos», «Los cuatro muleros», «Anda jaleo», «Las morillas de Jaén», «En el Café de Chinitas», entre otras, porque su poderosa memoria guardaba el cumplido conocimiento de muchísimas más canciones populares, que no siempre recogió por escrito. Como ha señalado Daniel Devoto (Vid. 1975: 24), probablemente Lorca encontró la inspiración para muchos de sus poemas en ese cancionero popular que rastreó con entusiasmo por toda España; no obstante, desde muy joven, Federico tuvo oportunidad de manejar diversos cancioneros musicales: el Cancionero musical popular español de Felipe Pedrell, el Cancionero popular de Burgos de Federico Olmeda, el Cancionero salmantino de Dámaso Ledesma o el Cancionero de Eduardo Ocón. Como indica su hermano Francisco (Vid. 1980: 428), Federico también conocía algunos cancioneros cultos bien medievales (el Cancionero de Palacio - probablemente por medio de Falla—, del que compró una edición en la Academia de San Fernando), o renacentistas (el Cancionero de Upsala, del que, al parecer, existía un ejemplar de la edición de Mitjana en la Residencia de Estudiantes, en la que fue residente entre 1919 y 1927).

Además, debió conocer bastante bien el libro Cantos populares españoles de Francisco Rodríguez Marín, editado en 1882, así como Días geniales o lúdricos de Rodrigo Caro (escrito hacia 1625, pero editado por vez primera mucho tiempo después), del que Lorca cita la definición que Caro (1978, II: 240) ya entonces dio de las nanas -las llamó «nina, nina, lala, lala»- ( «reverendas madres de todos los cantares y cantares de todas las madres»), en su famosa conferencia sobre las «Canciones de cuna españolas» (Vid. García Lorca, 1996, III: 113).

Como dijo José Bergamín (1940: 17), «Federico García Lorca es el poeta contemporáneo más íntimamente y, diríamos, pudorosamente arraigado en la gran poesía popular y tradicional española». Respecto a su interés temprano por las canciones populares, el propio poeta se refirió en los siguientes términos en la referida conferencia sobre las nanas:

En todos los paseos que yo he dado por España, un poco cansado de catedrales, de piedras muertas, de paisajes con alma, etc., etc., me puse a buscar los elementos vivos, perdurables, donde no se hiela el minuto, que viven un tembloroso presente. Entre los infinitos que existen, yo he seguido dos: las canciones y los dulces. Mientras una catedral permanece clavada en su época, dando una expresión continua de ayer al paisaje siempre movedizo, una canción salta de pronto, de ese ayer, a nuestro instante, viva y llena de latidos... (García Lorca, 1996, III: 113)

El interés de Lorca por la poesía popular, en general, y por la de tradición infantil en particular, podemos relacionarlo también con su firme creencia de que los conocimientos debían ponerse al servicio de la comunidad, rescatando las tradiciones, identificando lo que es propio de una cultura y común a todos los integrantes de una comunidad, creencias que formaban parte del ideario cultural y educativo de la Institución Libre de Enseñanza, que el propio Lorca volvió a poner en práctica en la década de los años 30 con el proyecto teatral de La Barraca. 
El principio de su oficio de escritor, incluso el origen de su trascendencia como poeta, habría que buscarlos en su infancia, no solo por lo que pudo aprender en su entorno familiar — casi siempre de voces femeninas-, sino también por lo que escuchó a niños y adultos, en plazas, calles, casas o campos: canciones populares, canciones infantiles y juegos acompañados de retahílas y sonsonetes, que le fascinaron desde muy niño.

Las transformaciones que se encuentran en la poesía folclórica, de modo especial en las canciones infantiles, han fascinado a los lectores, a los receptores, y no digamos a los lectores-poetas, que han encontrado en esos versos populares fuentes de inspiración, pues de ellos han tomado imágenes recreadas en sus poemas (Piñero, 2008: en línea).

García Lorca siempre tuvo presente, quizá con el ánimo decidido de no olvidarlos, los recuerdos de su niñez, en los que - ya dijimos - tuvieron gran presencia juegos y canciones infantiles, igual que la tuvieron los romances, los villancicos o las canciones de estación, que como los anteriores, quiso incorporarlos, en diversas ocasiones, a su poesía y a su teatro: «En García Lorca, las reminiscencias de la antigua lírica de tipo popular aparecen entreveradas con los ecos, más abundantes, de la canción popular actual, cobre todo de la infantil» (Frenk, 1971: 46).

\section{CANCIONES Y RETAHÍLAS INFANTILES EN EL TEATRO LORQUIANO}

Dice Ana Pelegrín (2003: 75) que «el especial deleite en la tradición oral infantil juega en el laboratorio juvenil de la poesía y el teatro lorquianos» - $\mathrm{y}$ señala las fechas de 1919 a 1926 como los años en que es más perceptible esa tradición—, aunque, como comprobaremos después, esa tradición infantil está presente también en obras escritas con posterioridad a esas fechas.

Fascinado por los elementos absurdos, a veces disparatados, que contenían muchas canciones populares infantiles, Lorca incorporó algunas de ellas, unas veces completas otras solo en unos pocos versos, tanto en su teatro como en algunos libros de poemas, lo que facilita que en el lector de esos textos lorquianos se active una experiencia de recepción literaria que, probablemente, tuvo en su niñez. Junto a esas incorporaciones, son frecuentes las referencias indirectas o las presencias meramente «casuales» de términos, expresiones o personajes del Cancionero Popular Infantil que, en los textos de Lorca, aparecen descontextualizados respecto al contexto en que vivieron -0 , a menudo, aún viven - en el propio Cancionero Infantil ${ }^{2}$. Un ejemplo de ello sería el poema «Naranja y limón», incluido en Canciones, libro escrito entre 1921 y 1924:
Naranja y limón.
¡Ay la niña
del mal de amor!
Limón y naranja.
¡Ay de la niña,
de la niña blanca!
(Cómo brillaba
el sol).

\footnotetext{
${ }^{2}$ Para consultar muchas de esas presencias «casuales» remito al estudio de Tadea Fuentes (1990), en el que, junto a referencias directas e indirectas a composiciones del Cancionero Infantil en la obra de Lorca, aparecen descritas también presencias de composiciones que corresponden al Cancionero Popular, de las que los niños participaron, en el mejor de los casos, como una parte más de la colectividad, pero no de manera exclusiva ni específica.
} 


\author{
Naranja. \\ En las chinas \\ de agua). \\ (García Lorca, 1996, I: 383)
}

La mera presencia del limón y la naranja no es suficiente para asociar el poema de Lorca con la canción/juego de corro, de la que existen numerosas versiones en toda España y en países americanos de habla hispana, como esta:
Al corro de la patata, comeremos ensalada, lo que comen lo señores, naranjitas y limones.
Achupé, achupé, sentadita me quedé.
(Cerrillo, 1994, II: 260)

En el análisis aquí realizado no hemos incluido esas presencias «casuales», pero sí los poemas (también versos que aparecen en sus obras de teatro) que García Lorca incorporó a bastantes de sus creaciones, comparándolos con composiciones del Cancionero Popular Infantil que, con toda probabilidad, él conocía, algunas de las cuales habría escuchado y aprendido personalmente, tanto en su infancia como en sus viajes por España en busca de canciones populares; pero otras, quizá, las había conocido en colecciones ya editadas por diversos folcloristas (Rodríguez Marín, 1882; Llorca, 1914; Martínez Torner, 1920, entre otros).

Son varias las presencias de versos y referencias directas de canciones populares infantiles en sus obras teatrales, desde sus inicios como escritor hasta el final. Veámoslas:

En Los títeres de Cachiporra. Tragicomedia de don Cristóbal y la señá Rosita, escrita en los veranos de 1921 y 1922, en el cuadro 6. ${ }^{\circ}$, escena 1. ${ }^{a}$, Rosita canta mientras llora:

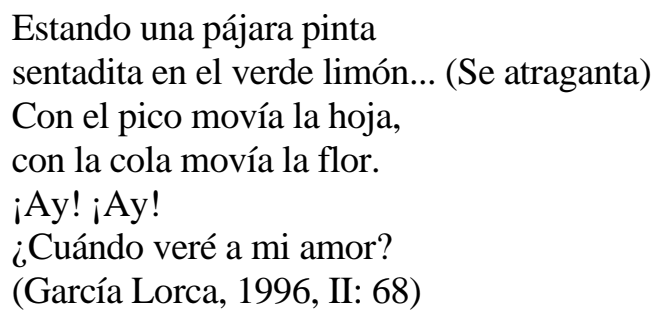

Es una canción escenificada infantil ${ }^{3}$, cuya amplia difusión por toda España y países latinoamericanos, ha provocado la existencia de diversas variantes, alguna de las cuales habría oído Lorca de niño guardándola en su memoria. Ya en el siglo XVII Alonso de Ledesma (1613: 89) habló de esta singular pájara («¿Dónde pica la pájara pinta, / dónde pinta?»), aunque, como es habitual en todo su libro (Juegos de Nochebuenas a lo divino), los motivos o personajes que toma del Cancionero Popular Infantil él los vuelve «a lo divino»: en este caso, la pájara pinta es el motivo sobre el que construye unas redondillas al Espíritu Santo. Por su parte, Fernando Llorca (1914: 81), unos años antes de que Lorca

\footnotetext{
${ }^{3}$ Sobre los tipos de composiciones del Cancionero Popular Infantil, remito trabajos anteriores: Cerrillo (1994, I: 36-56; y 2005: 33-44, en los que analizo como principales géneros: Nanas, primeros juegos mímicos, canciones escenificadas, oraciones, suertes, adivinanzas, burlas y trabalenguas).
} 
incluyera en su texto esos versos, recoge la cantinela como canción de corro infantil, describiéndola con todo detalle de la siguiente manera:

Corro: Estaba la pájara pinta

a la sombra de un verde limón;

con el pico recoge la hoja,

con el pico recoge la flor.

¡Ay, mi amor!

La niña pájara pinta, en el centro del corro, hace lo que dice la canción:

Me arrodillo a los pies de mi amante,

fiel y constante;

dame una mano,

dame la otra,

dame un besito

de tu linda boca.

Daremos la media vuelta,

daremos la vuelta entera,

daremos un paso atrás.

Y tapándose la cara añade:

Pero no, pero no, pero no,

pero no, que me da vergüenza;

pero sí, pero sí, pero sí,

amiguita, te quiero a ti.

Se besan, y la niña que eligió es ahora la pájara pinta.

Una versión parecida, aunque sin las precisiones descriptivas del juego que hace Lorca, recogió unos años antes Rodríguez Marín (1882. Vid. 1981, I: 114).

La pájara pinta vuelve a aparecer, aunque solo como una mera referencia, en la estampa segunda (escena III) de Mariana Pineda, cuando la protagonista se dirige a los niños con estos versos:

Soñar en la verbena y el jardín

de Cartagena, luminoso y fresco,

y en la pájara pinta que se mece

en las ramas del agrio limonero (...)

(García Lorca, 1996, II: 120)

También en Los títeres de Cachiporra. Tragicomedia de don Cristóbal y la señá Rosita, cuadro quinto (escena I), nos encontramos con la retahíla «Tira y afloja»:

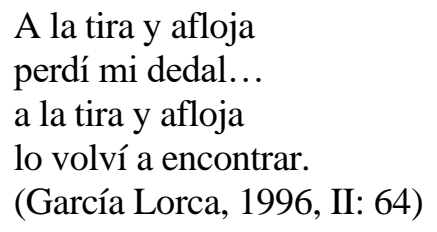

Es una retahíla que acompaña un juego con cuerda o pañuelo en el que participan dos o varios chicos, que tiran del objeto o aflojan, cuando se dice una de las dos palabras. El juego, que ya lo mencionó Covarrubias (1611: 963a), lo recogió Ana Pelegrín (1996: 289) en una versión muy parecida a la de Lorca: 


\begin{abstract}
A la tira y afloja perdí mi caudal. A la tira y afloja lo volví a ganar. ¡Tira! ¡Afloja!
\end{abstract}

Algún verso de la retahíla vuelve a aparecer en el acto III (cuadro I) de Así que pasen cinco años, escrita por Lorca en 1931 — aunque es una referencia indirecta—, cuando el autor pone en boca de una muchacha:
Verdad.
Perdí mi corona,
perdí mi dedal,
y a la media vuelta
los volví a encontrar.
(García Lorca, 1996, II: 372)

En El retablillo de don Cristóbal (García Lorca, 1996, II: 403-405), escrita entre fines de 1931 y principios de 1934, la Madre y don Cristóbal mantiene un diálogo, a ratos absurdo, en el que se intercambian algunos versos en los que podemos percibir elementos de algunas «burlas» infantiles:
Don Cristóbal: Una onza de oro de las que cagó el moro, una onza de plata de las que cagó la gata ${ }^{4}$.
Madre: $\quad$ (...) Viejo, viejo pellejo.

Don Cristóbal: $\quad$ Y usted es una vieja, que se limpia el culito con una teja.

El diálogo antes aludido se enriquece con la inclusión del canto del «vito» por parte de Rosita:
Con el vito, vito, vito,
con el vito que me muero,
cada hora, niño mío,
estoy más metida en fuego.

Un canto que no es, específicamente, de tradición infantil, que García Lorca también incorporó en Los títeres de Cachiporra (García Lorca, 1986, II: 49), y que podemos aún escuchar en versiones que no difieren mucho de esa del poeta granadino:

Con el vito, vito, vito, con el vito, vito, va, no me mires a la cara, que me pongo colorá 5 .

\footnotetext{
${ }^{4}$ Una versión idéntica recogimos en Cuenca en 1973. Informante Palmira Villaseñor, 78 años.

${ }^{5}$ Recogida en Cuenca, 2004. Informante: Carmen Orozco, 86 años.
} 
Por último, en La casa de Bernarda Alba, escrita en los últimos meses de la vida del poeta granadino, podemos leer, por boca de M. ${ }^{\text {a }}$ Josefa (acto III) esta doble burla:

Bernarda, cara de leoparda.

Magdalena, cara de hiena.

En el Cancionero Infantil son varios los ejemplos de burlas que se dicen a personas, por razón de su nombre propio:

— ¿Has visto a la Dolores?

— ¿Qué Dolores?

- La que tiene la cara

de mil colores ${ }^{6}$.

También el acto III de La casa de Bernarda Alba, Adela entona esta oración/conjuro:

Santa Bárbara bendita,

que en el cielo estás escrita

con papel y agua bendita.

(García Lorca, 1996, II: 624)

Es una oración que, popularmente, se dice cuando se divisa un relámpago en el cielo o se ve «correr» una estrella en la noche, como si ello fuera anuncio de algún mal, de ahí que se pueda interpretar también como conjuro. Son varias las versiones que existen de esa retahíla, muy parecidas todas ellas, como esta que recogí en Cuenca en 1984?:

Santa Bárbara bendita, en el cielo hay una ermita, con papel y agua bendita.

\section{BIBLIOGRAFÍA}

Alonso DE LedeSMA, (1613): Juegos de noches buenas a lo divino, Madrid, Alonso Martín.

Bergamín, José (1940): «Prólogo», en Poeta en Nueva York, México, Séneca.

CANO, José L. (1988): García Lorca, Barcelona, Salvat.

CERRILlo, Pedro C. (1994): Lírica popular española de tradición infantil, I y II, Tesis doctoral, Cuenca, Ediciones de la Universidad de Castilla La Mancha.

Covarrubias, Sebastián de (1987 [1611]): Tesoro de la lengua española, Barcelona, Altafulla.

FRENK, Margit (1971): Entre foklore y literatura (Líruca hispánica antigua), México, El Colegio de México.

\footnotetext{
${ }^{6}$ Para consultar otras burlas provocadas por nombres propios de persona, Vid. Cerrillo, 1994, II: 378392.

${ }^{7}$ Informante: Ana Torremocha, 59 años
} 
FuENTES, Tadea (1990): El folklore infantil en la obra de Federico García Lorca, Granada, Universidad de Granada.

GARCía LORCA, Federico (1996): Obras completas, I-IV, Miguel García Posada (Ed.), Barcelona, Círculo de Lectores / Galaxia Gutenberg,

GARCÍA LORCA, Francisco (1980): Federico y su mundo, Madrid, Alianza Tres.

GuILLÉN, Jorge (1974): «Prólogo», en Obras Completas, Arturo del Hoyo (ed.), Madrid, Aguilar, pp. XV-LXXXI.

LlORCA, Fernando (1914): Lo que cantan los niños, Ed. facsimilar de 1998, Valencia, Prometeo.

MARTíNEZ TORNER, E. (1920): Cancionero musical de la lírica popular asturiana, Madrid, Establecimiento Tipográfico Nieto y Cía.

PElegRín, Ana (1996): La flor de la maravilla. Juegos, recreos, retahílas, Madrid, Fundación Germán Sánchez Ruipérez.

PELEGRÍN, Ana (2003): «Lorca y las canciones de cuna españolas», en Boletín de la Institución Libre de Enseñanza, p. 52.

PIÑERO, Pedro (2008): «Lorca y la canción popular. Las tres hojas: de la tradición al surrealismo», Culturas Populares, 6.

URL: <http://www.culturaspopulares.org/textos6/articulos/pinero.htm>

RODRÍGUEZ MARÍN, Francisco (1882): Cantos populares españoles, I, Madrid, Atlas.

Fecha de recepción: 24 de abril de 2019

Fecha de aceptación: 8 de septiembre de 2019

9 